\title{
Antecedents of academic emotions: Testing the internal/external frame of reference model for academic enjoyment ${ }^{\text {th }}$
}

\author{
Thomas Goetz ${ }^{\mathrm{a}, *}$, Anne C. Frenzel ${ }^{\mathrm{a}}$, Nathan C. Hall ${ }^{\mathrm{b}}$, \\ Reinhard Pekrun ${ }^{\text {a }}$ \\ ${ }^{a}$ Department of Psychology, University of Munich, Leopoldstr. 13, D-80802 Munich, Germany \\ ${ }^{\mathrm{b}}$ University of California, Irvine, CA, USA
}

\begin{abstract}
The present study focused on students' academic enjoyment as predicted by achievement in multiple academic domains. Assumptions were based on Marsh's internal/external (I/E) frame of reference model and Pekrun's control-value theory of achievement emotions, and were tested in a sample of 1380 German students from grades 5 to 10. Students' academic enjoyment, self-concept, and achievement were assessed in relation to mathematics and verbal language classes. In line with assumptions of the I/ E model, mathematics performance assessed in the previous academic year positively predicted enjoyment in mathematics classes, and negatively predicted enjoyment in language classes. Language class performance positively predicted enjoyment in language classes, and negatively predicted enjoyment in mathematics classes. Corroborating assumptions derived from Pekrun's control-value theory, achievement/enjoyment relations were mediated by academic self-concepts. Despite stereotypic gender differences in mean values, linkages between constructs were invariant across genders.
\end{abstract}

(c) 2007 Elsevier Inc. All rights reserved.

Keywords: Achievement emotion; Positive emotion; Enjoyment; Self-concept; Internal/external frame of reference model

\footnotetext{
is This study was supported by a doctoral fellowship from the Social Sciences and Humanities Research Council of Canada (SSHRC) to Nathan C. Hall.

* Corresponding author. Fax: +49 8921805250.

E-mail address: goetz@edupsy.uni-muenchen.de (T. Goetz).
} 


\section{Introduction}

Until recently, emotional experiences related to learning and achievement have been neglected in educational research. In the past 10 years, however, there has been a discernable increase in theoretical and empirical contributions on emotions in education. This increased interest is reflected in three recent special issues (Efklides \& Volet, 2005; Linnenbrink, 2006; Schutz \& Lanehart, 2002) and an edited volume (Schutz \& Pekrun, in press) on this topic. However, despite this increased interest in academic emotions, relatively few studies have focused on positive emotions like enjoyment, pride, and hope as experienced in educational settings (Pekrun, Goetz, Titz, \& Perry, 2002a). To date, educational studies have mainly focused on negative emotional experiences such as test anxiety (Zeidner, 1998). The lack of educational research on positive emotions is surprising, given that the importance of positive emotions has been documented by a large number studies conducted in the context of positive psychology (Seligman \& Csikszentmihalyi, 2000).

Existing research has explored motivational constructs that are linked to positive emotions, such as interest and intrinsic values. However, while these studies assessed constructs that are considered to be related to emotions (Roseman \& Smith, 2001), they did not examine the nature of positive emotions per se (Hidi, Renninger, \& Krapp, 2004). Consequently, this related body of research should be distinguished from research focusing explicitly on emotions, and more specifically, students' positive emotional experiences.

Pekrun et al. (2002a) suggested that positive emotions are worthy of investigation because they "help to envision goals and challenges, open the mind to thoughts and problem-solving, protect health by fostering resiliency, create attachments to significant others, lay the groundwork for individual self-regulation, and guide the behaviour of groups, social systems, and nations" (p. 149). In the same vein, Fredrickson (2001) stated that "positive emotions are worth cultivating, not just as end states in themselves but also as a means to achieving psychological growth and improved well-being over time" (p. 218).

More specifically, positive emotions play a pivotal role within educational settings. Pekrun, Goetz, Titz, and Perry (2002b) highlighted the relevance of positive academic emotions with respect to self-regulation, strategy use, motivation, and activation of cognitive resources in students. Aspinwall (1998) also argued that positive academic emotions can effectively contribute to self-regulatory processes in students. Furthermore, positive emotions have been found to positively relate to student involvement in terms of course enrollment, career aspirations, and occupational choices in specific domains (cf., Wigfield, Battle, Keller, \& Eccles, 2002). For example, if students experience fewer positive emotions related to mathematics, they are significantly less likely to pursue a career in this domain, irrespective of their performance in this subject area. Taken together, extant research suggests that positive emotional experiences play an important role in academic achievement settings, and can have a considerable impact on students' cognitions, behavior, and ultimate success in the academic domain.

Given the clear relevance of positive emotions for education, the antecedents of students' positive emotional experiences are an important avenue for further investigation. More specifically, it is by examining why students experience specific positive emotions in educational settings that we can better offer suggestions for designing academic environments that foster positive affective experiences such as enjoyment, hope, and pride. However, with the exception of research on emotions in achievement settings based on 
attribution theory (see Weiner, 1985, 2001), there is a lack of research exploring the antecedents of students' positive affect.

The present study focuses on one central positive academic emotion, learning-related enjoyment, as experienced in two academic domains, namely mathematics and language classes. Conceptualizing academic emotions as related to specific academic subjects is based on our previous research indicating that academic enjoyment is largely organized in a domain-specific manner (Goetz, Pekrun, Hall, \& Haag, 2006). The study examined the role of academic performance as a critical antecedent of students' positive emotional experiences, which, next to teachers' reactions such as praise and punishment, is the most important form of competence feedback among students (Carol, 1986, 1989).

Concerning the relations between grades in different domains, and between experiences of academic enjoyment in these domains, we based our assumptions on Marsh's (1986, 1990) internal/external frame of reference model. We also investigated the relations between experiences of enjoyment in mathematics and language classes based on this analytical model, thus re-examining the domain-specific nature of academic enjoyment. Our second research question concerned whether the I/E model represents a valid conceptual framework for understanding how students' experiences of enjoyment in mathematics and language classes relate to their achievement in these classes. Third, based on Pekrun's (2000, 2006) control-value theory of achievement emotions, we analyzed whether the assumed achievement/enjoyment relations in mathematics and language classes were mediated by the corresponding academic self-concepts. Finally, we tested for gender differences in mean levels of achievement, self-concepts, and enjoyment in each subject area, and also compared the structural relations between these variables separately for male and female students, in order to assess the cross-gender universality of findings.

\section{Theoretical framework}

\subsection{The internallexternal frame of reference model}

Typically, math and verbal academic self-concepts are uncorrelated, despite strong correlations between math and verbal achievement, as well as between these achievement outcomes and their respective self-concepts. Marsh $(1986,1990)$ developed the internal/external frame of reference model to account for this seemingly paradoxical pattern of relations. According to this model, the subjective evaluation of one's performance is based not only on social comparisons (external frame of reference), but also on cross-domain or dimensional comparisons (internal frame of reference) implying a comparison of one's own achievement in a subject area with achievement in other subjects. Empirically, this assumption has repeatedly been confirmed by findings showing negative relationships between achievement indicators in one subject and self-concept in another subject, when achievement in the second subject was controlled for (e.g., Skaalvik \& Rankin, 1995). Typically, the negative effects of achievement on self-concepts across domains are smaller than the positive effects within a domain.

For the achievement/self-concept relations as described in the I/E model, course grades can be assumed to have stronger effects on academic self-concepts than standardized test scores. Grades are a more salient source of feedback for students than standardized test scores (Marsh, 1987; Wylie, 1979). Strong evidence for this theoretical assumption was 
found in the context of mathematics in a recent study by Marsh, Trautwein, Lüdtke, Köller, and Baumert (2005, German 7th-grade students).

A critical question concerning the I/E model involves the generalizability of the model's assumptions to constructs other than self-concept. Although this model was originally developed within an academic self-concept framework, there is some empirical evidence that supports its validity concerning other phenomena, including intrinsic motivation and effort (Skaalvik \& Rankin, 1995), as well as anxiety (Marsh, 1988a). However, knowledge is lacking as to whether the I/E model represents a valid conceptual framework for explaining the relations between achievement and emotion constructs other than anxiety. The present study aims to reduce this research deficit by testing whether the assumptions of the $\mathrm{I} / \mathrm{E}$ model are valid for experiences of enjoyment in academic settings.

\subsection{Achievement and emotions in different academic domains}

As the patterns of relations between achievement and emotions in different academic domains are the focus of the present study, the results of previous empirical studies concerning these relations are outlined in the following sections. More specifically, we summarize the findings of existing research that examined (1) cross-domain relations between academic achievement outcomes (e.g., achievement in mathematics and language classes); (2) cross-domain relations between academic emotions (e.g., enjoyment in mathematics and language classes); (3) achievement/emotion relations within domains (e.g., achievement and enjoyment in mathematics); and (4) achievement/emotion relations across domains (e.g., achievement in mathematics and enjoyment in verbal classes).

\subsubsection{Cross-domain relations between academic achievement outcomes}

Many studies have shown that achievement tends to show positive interrelationships across different academic domains (Möller \& Köller, 2004). The strength of these relations has been found to depend on the similarity of the content areas, the methods used to assess achievement, as well as the reliability and validity of the measures used. Correlations between math and verbal achievement have been investigated most frequently. As reported by Möller and Köller (2004) who reviewed 34 studies analyzing this relationship, correlations were found to range from $r=.31$ to .94 (mean correlation of $r=.63$ ). Similar findings were reported by Goetz, Pekrun, et al. (2006) who found a mean correlation of $r=.50$ between final grades in core subject areas (i.e., mathematics, English, German, and Latin) in a sample of German middle-school students. As such, empirical findings show relatively high intercorrelations between achievement outcomes in different academic domains.

\subsubsection{Cross-domain relations between academic emotions: Implications of Pekrun's control- value theory}

The degree to which students' emotional experiences differ along subject-specific lines is an issue of particular relevance to theory, research, and educational practice. For example, it is important to know whether a single, domain-general measurement of emotions will suffice as a method for assessing students' emotional experiences across a variety of subject areas. From a practical perspective, it is relevant, for example, for a mathematics teacher to know whether a student who is bored in math classes also feels bored in other classes. If the student was experiencing boredom in most subject areas, an educational intervention 
would likely be structured differently than if the student was bored exclusively in math classes.

Recent research on other motivational constructs such as self-efficacy expectancies, causal attributions, academic self-concepts, task values, and achievement goals suggest that these motivational constructs are organized in a domain-specific manner (e.g., AbuHilal \& Bahri, 2000; Bong, 1998, 2001; Marsh, 1984, 1986, 1993; Marsh \& Yeung, 1996; Möller \& Köller, 2001; Stevenson \& Newman, 1986; see Bong \& Skaalvik, 2003 for academic self-concept and self-efficacy). This assertion is further supported by the review by Möller and Köller (2004) who found a very low mean correlation of $r=.10$ (range: $r=-.13$ to .22) for math and verbal self-concepts across studies.

In contrast, evidence on the domain specificity of emotional experiences is largely lacking. In fact, with the exception of research on mathematics and science anxiety, most studies conducted on achievement-related anxiety are based on the implicit assumption that emotions are not domain-specific, and have employed domain-general designs (Zeidner, 1998). There are a few studies on test anxiety that report findings on domain specificity. However, with the exception of research by Marsh (1988a) and Marsh and Yeung (1996), this issue was not directly addressed (see Everson, Tobias, Hartman, \& Gourgey, 1993; Stipek \& Mason, 1987).

In our own research exploring the domain specificity of students' academic achievement emotions (Goetz, Frenzel, Pekrun, \& Hall, 2006; Goetz, Pekrun, et al., 2006; Pekrun, Goetz, Titz, \& Perry, 2002c) we used Pekrun's control-value theory of achievement emotions as a theoretical framework (Pekrun, 2000, 2006). This theory implies that two types of appraisals are of specific relevance for the arousal of achievement-related emotions: appraisals of control over achievement activities and their outcomes, and of the value of these activities and outcomes. Achievement-related expectancies (including self-efficacy and outcome expectancies; Pekrun, 1992), causal attributions for achievement outcomes (Weiner, 1985), and self-concepts of ability are seen as control-related cognitions, and subjective values as well as achievement goals are seen as implying value appraisals. Any achievement-related emotion is assumed to be a joint product of control and value appraisals, including students' enjoyment which is posited to be aroused when learning is perceived as both controllable and valuable (Pekrun, 2006; Pekrun, Elliot, \& Maier, 2006). Since self-efficacy expectancies, causal attributions, self-concepts of ability, subjective task values, and achievement goals have all been found to be domain-specific, one of the corollaries of the control-value theory is that achievement emotions should also show weak between-domain relations.

In line with this assumption, between-domain correlations were found to be non-significant and near zero for middle-school students' academic enjoyment in mathematics, languages (German and English), music, and sports, and low for anxiety in the study reported by Pekrun et al. (2002c). The two follow-up studies by Goetz, Frenzel, et al. (2006) and Goetz, Pekrun, et al. (2006) examined enjoyment, anxiety, and boredom in up to six subject domains. These two studies found similar results, with enjoyment showing the strongest degree of domain specificity among the emotions assessed.

\subsubsection{Achievementlemotion relations within domains}

Nearly all of the studies exploring achievement/emotion relations within domains have focused on academic anxiety, and most with respect to anxiety in mathematics classes. Typically, negative relations of medium size were found in these investigations. In his 
meta-analysis, Hembree (1990) reported a mean correlation of $r=-.31$ between anxiety and achievement in mathematics. Similarly, Ma (1999) found a mean correlation of $r=-.27$ between these constructs in a more recent meta-analysis.

Although little research has investigated the within-domain relations between academic achievement and enjoyment, existing data suggests relations of medium size for enjoyment as well (see Pekrun et al., 2002b). For example, Helmke (1993) reported positive relations between learning-related enjoyment and achievement in mathematics in grades 1 to 4 $(r=.35 / .31 / .63 / .67$ in grades 1/2/3/4). In a longitudinal study, Goetz et al. (2004) found significant effects of math achievement in grade 5 on experiences of math-related enjoyment in grade 6, even when controlling for enjoyment in grade 5. Jerusalem and Mittag (1999) reported correlations between grades and enjoyment in mathematics ranging from $r=.27$ .68 (grades 7-12). Similarly, correlations between enjoyment and achievement in math were $r=.38$ and .43 in two recent studies by Goetz (2004, grades 5-10). In sum, empirical results clearly indicate positive within-domain relationships between academic achievement and students' emotions.

\subsubsection{Achievementlemotion relations across domains}

Concerning cross-domain relations between achievement outcomes and experiences of enjoyment, evidence seems to be lacking. In two preliminary studies, Goetz (2004) reported correlations of $r=-.01$ and -.04 between achievement in language classes (German) and enjoyment in mathematics, and correlations of $r=-.05$ and .06 between language achievement and anxiety in mathematics. These results suggest that between-domain relations are nonsignificant, and are in line with findings of test anxiety research showing negligible relations between language achievement and mathematics anxiety (e.g., Hembree, 1990; Marsh, 1988a).

To sum up, existing research shows that there are relatively strong cross-domain relations between achievement outcomes (e.g., achievement in math and English), and relatively strong within-domain relations between achievement outcomes and enjoyment (e.g., achievement in math and enjoyment in math). Furthermore, evidence from preliminary studies suggests that enjoyment as experienced in different subject areas is unrelated across domains (e.g., enjoyment in math and English), and that achievement and enjoyment also are unrelated across domains (e.g., English achievement and enjoyment in math).

\subsection{The I/E model for academic enjoyment: Self-concept as a mediator between achievement and enjoyment}

The pattern of relations between achievement and emotions in different academic domains found in previous research suggests that the I/E model may be used to describe these relations. Further, we believe that the mechanisms underlying these relations can best be explained by integrating assumptions of the I/E model with assumptions from Pekrun's control-value theory of achievement emotions. Whereas the I/E model explains how achievement shapes students' academic self-concepts, the control-value theory can be used to explain how self-concepts impact students' emotions (Pekrun, 2000, 2006; Pekrun, Frenzel, Goetz, \& Perry, in press).

As outlined above, the control-value theory posits that students' academic emotions are (partially) determined by appraisals of subjective control over achievement-related activities and outcomes. Such appraisals are implied by achievement-related causal expectancies, 
causal attributions, and self-concepts of ability (Pekrun, 2006; Skinner, 1996). Regarding self-concepts, students' academic self-concepts pertain to having (or not having) the abilities that are necessary to exert control over one's learning and achievement. Academic selfconcepts thus imply control-related appraisals that affect students' achievement emotions.

As one important implication, since academic self-concepts are themselves dependent on students' actual achievement outcomes, they are expected to mediate effects of these outcomes on students' academic emotions. Furthermore, due to this mediational mechanism, the within- and cross-domain relations of academic achievement and emotions can be assumed to be structurally equivalent to the within- and cross-domain relations of academic achievement and self-concepts of ability.

More specifically, with respect to students' academic enjoyment, it is assumed that selfappraisals of competency make it possible to enjoy achievement-related activities in a given domain, and to look forward to attaining favorable outcomes in this domain. Conversely, if a student feels unable to succeed, learning activities cause frustration or boredom instead of enjoyment, and pleasurable outcomes would not be expected. By implication, we assumed that students' academic self-concepts exert positive effects on their academic enjoyment, and that these self-concepts mediate any effects of achievement on enjoyment. These assumptions also imply that the within- and cross-domain relations of achievement and enjoyment are structurally equivalent to the relations between achievement and selfconcepts as described in the I/E model. In other words, we expected positive relations between achievement and enjoyment within domains, as well as negative relations between achievement in one domain and enjoyment in another when achievement in the second domain was controlled for.

\subsection{Gender differences in achievement, self-concept, and enjoyment}

\subsubsection{Gender differences in mean levels}

Compared to boys, girls typically receive similar or slightly lower grades and scores on standardized mathematics tests (cf., Hanna, 2000; Marsh et al., 2005). Concerning achievement in language courses, however, girls typically perform better on standardized tests, and receive better grades than boys, although these differences are often relatively small (Marsh \& Yeung, 1998; Stumpf \& Stanley, 1998). With respect to mean levels of academic self-concepts, there is empirical evidence indicating that girls, as compared to boys, show a significantly lower level of academic self-concept in mathematics (Hyde, Fennema, Ryan, Frost, \& Hopp, 1990; Pekrun \& Zirngibl, 2004), and a higher level of academic self-concept in language-oriented school subjects (Crain, 1996). For both the mathematics and the verbal domains, results indicate that gender differences in academic self-concepts are stronger in terms of effect size than are differences in academic achievement.

Empirical evidence concerning gender differences in academic enjoyment, however, is lacking. A recent study by Frenzel, Pekrun, and Goetz (in press) suggested that girls experience less enjoyment in mathematics than boys. Further, a preliminary study by Goetz (2004) showed that girls experienced more enjoyment in language classes than boys, thus mirroring the gender differences in self-concepts of ability.

\subsubsection{Gender differences in structural relations}

Knowledge concerning the gender specificity of structural relations between academic achievement, self-concept, and enjoyment may be critical for understanding the causes of 
mean level differences between the genders. Some findings suggest that gender can moderate relations between achievement and cognitive-affective variables (e.g., Deaux, 1977; Meyer \& Koehler, 1990; Zeidner \& Safir, 1989). However, there seems to be more empirical support for the assumption of cross-gender universality of these relations, that is, the assumption that relations are structurally equivalent across girls and boys (e.g., Meece, Wigfield, \& Eccles, 1990; Seegers \& Boekaerts, 1996). More specifically, in two recent longitudinal studies, Marsh et al. (2005) showed that the relations addressed by the I/E model were equivalent across the two genders.

Findings of other studies also corroborated the structural equivalence of achievement/self-concept relations in girls and boys. In a review of 128 studies that examined relations between self-beliefs and measures of performance and achievement, Hansford and Hattie (1982) found that gender was not a significant moderator of these relationships. In a similar vein, a meta-analytic review of 60 independent longitudinal studies reported by Valentine, DuBois, and Cooper (2004) found that gender did not moderate the size of effects of self-beliefs on subsequent academic achievement. Concerning gender differences of relations between academic achievement and enjoyment, and between academic self-concept and enjoyment, we know of only one single study (Frenzel et al., in press). This study examined cross-gender universality using structural equation modeling, and found no significant gender differences for relations between math-related competence beliefs and math enjoyment, and between math enjoyment and mathematics grades.

\section{Present research questions}

Our research questions concerned the relationships between achievement, self-concept, and enjoyment in mathematics and German language classes. We used a predictive design for testing assumptions as derived from Marsh's (1986) internal/external frame of reference model and Pekrun's (2000, 2006) control-value theory of achievement emotions. In addition, we analyzed gender differences in the mean levels of these variables, and in their structural interrelations. Our specific hypotheses are outlined in greater detail below.

Hypothesis 1. Domain specificity. As described above, preliminary empirical findings, and the assumptions of the control-value theory of achievement emotions, imply that students' emotional experiences are organized in domain-specific ways. Therefore, we assumed that the correlations between math and verbal enjoyment (relating to the domains of mathematics and German), as well as the correlations between math and verbal self-concepts, would be rather weak. In contrast, and in line with previous findings, students' grades in these two subject areas were assumed to be strongly correlated.

Hypothesis 2. Achievementlenjoyment relations. Our second research question related to the validity of the internal/external frame of reference model as applied to academic enjoyment. We assumed that there are positive and significant within-domain relations between achievement outcomes and enjoyment. When controlling for these within-domain relationships, negative cross-domain relations between achievement in one subject and enjoyment in the other subject were expected. In other words, when controlling for within-domain effects, higher levels of performance in one domain was assumed to correspond with lower levels of enjoyment in the other domain. 
Hypothesis 3. Mediation processes. Our third research question referred to the role of selfconcept in this assumed pattern of within- and cross-domain relations. As outlined above, the control-value theory of achievement emotions implies that the effects of achievement on academic enjoyment are largely mediated by control-related appraisals, including academic self-concepts (Pekrun, 2000, 2006). Students with high math achievement were expected to have higher mathematics self-concept, and therefore, to experience more enjoyment in math classes. At the same time, they were expected to have a lower verbal self-concept and, consequently, experience lower levels of enjoyment in language classes. Conversely, students with high language achievement were expected to have higher verbal self-concepts and more enjoyment in language classes, and to have lower self-concepts and less enjoyment in mathematics classes.

Hypothesis 4. Gender differences. Finally, our fourth research question related to gender differences in academic achievement, self-concept, and enjoyment. Based on previous findings, we assumed that girls, as compared to boys, would show the same or slightly lower grades, lower self-concepts, and less enjoyment in mathematics, as well as higher grades, self-concepts, and enjoyment in German. In line with previous studies, we assumed that these gender differences in self-concept and enjoyment would be small in terms of effect size. Furthermore, in spite of mean level differences, we anticipated equivalence of structural relations between academic achievement, self-concepts, and enjoyment (cross-gender universality of structural relations).

\section{Method}

\subsection{Sample}

The sample consisted of 1380 students (49.5\% female) from 56 German classrooms in grades 5-10 (grade 5: $n=233,55.1 \%$ female; grade 6: $n=238,53.6 \%$ female; grade 7 : $n=237,47.3 \%$ female; grade $8: n=268,40.7 \%$ female; grade $9: n=238,53.6 \%$ female; grade 10: $n=168,56.0 \%$ female). The sample represented the three achievement-defined tracks of the German school system, including 24 classes from the lower track $(n=498,50.3 \%$ female), 18 classes from the middle track ( $n=484,47.7 \%$ female), and 14 classes from the top track ( $n=398,54.2 \%$ female). Students' mean age was 12.56 years $(\mathrm{SD}=1.80)$.

\subsection{Study measures}

\subsubsection{Enjoyment of mathematics and language classes}

For assessing enjoyment in mathematics classes, we employed the class-related subscale of the enjoyment scale of the Achievement Emotions Questionnaire for Mathematics (AEQ-M; Goetz, 2004; Pekrun, Goetz, \& Frenzel, 2005; see Pekrun, Goetz, \& Perry, 2005, and Pekrun et al., 2002b, for the Achievement Emotions Questionnaire [AEQ]; see also Pekrun et al., 2004 for the Test Emotions Questionnaire, TEQ, comprising the test emotions scales of the AEQ). The scale consisted of three items (e.g., "I enjoy my math classes"). For enjoyment related to language classes (i.e., German), the same items were used, with the term "German" used instead of "math." The response format for both scales consisted of a 5-point Likert scale ranging from 1 (strongly disagree) to 5 (strongly agree). Reliabilities were $\alpha=.88(M=8.66 ; \mathrm{SD}=3.32)$ for the math-related enjoyment scale and 
$\alpha=.91(M=8.74 ; \mathrm{SD}=3.57)$ for the language enjoyment scale. Means, standard deviations, and intercorrelations for all enjoyment items are shown in the Appendix A. A previous mathematics-specific study by Goetz (2004, $N=784$, grades $5-10,54 \%$ female) indicated high validity of the class-related enjoyment scale (correlations were $r=.63$ with learning-related enjoyment, .70 with test-related enjoyment, -.59 with class-related boredom, .65 with academic self-concept, and .41 with achievement).

\subsubsection{Math and verbal academic self-concept}

For the assessment of students' academic self-concept in mathematics and language classes (German), we used short versions (each three items) of two scales of the Self Description Questionnaire (SDQ; Marsh, 1988b). In order to avoid redundancy of our enjoyment and self-concept scales, self-concept items focusing exclusively on cognitive aspects, and not on affective aspects, were employed (e.g., "I get good marks in mathematics," "I get good marks in German," respectively; see Bong \& Clark, 1999, for a discussion of the distinction between cognitive-evaluative and affective components of academic selfconcepts).

The response format for both scales consisted of a 5-point Likert scale ranging from 1 (strongly disagree) to 5 (strongly agree). Reliabilities were $\alpha=.85(M=8.70$; $\mathrm{SD}=3.32)$ for the math-related self-concept scale and $\alpha=.82(M=10.07 ; \mathrm{SD}=3.03)$ for the language self-concept scale. Means, standard deviations, and intercorrelations for all self-concept items are shown in the Appendix A. Findings of a mathematics-specific study by Goetz and Frenzel (2006, $N=1005$, grades $5-10,51 \%$ females) corroborate the validity of the mathematics self-concept scales (correlations of $r=.85$ with the academic self-concept scale of the "Sears Self-Concept Inventory" [German version; Ewert, 1979], .57 with class-related enjoyment, -.50 with class-related anxiety, and .56 with academic achievement).

\subsubsection{Academic achievement}

Students' performance in mathematics and German classes was assessed through final grades from the previous school year. These grades had been administered to the students about four months prior to the assessment of academic enjoyment and self-concept. In the German school system, final grades in a subject are typically based on four written exams administered over the course of an academic year, combined with scores on course-specific oral examinations. Grades range from 1 (very good) to 6 (insufficient), with higher numbers representing poorer achievement outcomes. To allow for grade values to be interpreted more intuitively, we inverted them so that higher numbers indicated better achievement. Means, standard deviations, and intercorrelations for the achievement measures of the entire sample are shown in the Appendix A.

\subsection{Procedure}

Participants were tested in a classroom setting and took part on a voluntary basis, receiving neither financial rewards nor feedback of results. An experimenter was present throughout the entire testing session which lasted approximately $45 \mathrm{~min}$. Instructions were given verbally by the experimenters and were also written on the test material. To prevent participants from explicitly focusing on comparisons between the two subject areas, items referring to mathematics were located in the first part of the questionnaire, and items 
related to German instruction in the second part of the questionnaire (see Bong, 1998 for a similar procedure).

\subsection{Rationale for data analysis}

For testing assumptions concerning the domain-specific organization of academic enjoyment and academic self-concept in math and language classes (Hypothesis 1), we calculated zero-order correlations between these scales. For testing assumptions on the relations between achievement outcomes, self-concepts, and enjoyment within and across domains (Hypotheses 2 and 3), we used structural equation modeling (LISREL 8.53; Jöreskog \& Sörbom, 2002). We first calculated a model in which only the within- and crossdomain relations of achievement and enjoyment in mathematics and German (verbal) were included (Model A). In a second step, we added the two self-concept variables to the model to test if they mediated effects of achievement on enjoyment (Model B). Finally, we evaluated a third model (Model C) which fixed coefficients for effects that were theoretically assumed to be zero. More specifically, the four coefficients reflecting the direct paths from achievement to enjoyment (two within- and two between-domain paths), and the two cross-domain path coefficients for effects of self-concepts on enjoyment were constrained to zero.

We tested the fits of all our models with the classic $\chi^{2}$ statistic and selected fit indices (Non-normed fit index, NNFI [ = Tucker-Lewis Index, TLI], Tucker \& Lewis, 1973; comparative fit index, CFI; Bentler, 1990; root mean square error of approximation, RMSEA; Steiger \& Lind, 1980). Both the NNFI and the CFI are incremental indices with goodness of fit scaled on a $0-1$ scale. The zero-point is defined by a null model, in which all of the measured variables are assumed to be uncorrelated, and the 1.0 point reflects a "perfect" fit. NNFIs and CFIs greater than .95 indicate an acceptable model fit (Hu \& Bentler, 1999). CFI and NNFI differ from each other in that the CFI is insensitive to model complexity, whereas the NNFI corrects the fit according to model complexity. The RMSEA takes the error of approximation in the population into account and is also sensitive to the complexity of the model. RMSEAs less than .06 indicate good fit and values as high as .08 represent reasonable error of approximation in the population (Hu \& Bentler, 1999).

Concerning competitive testing of Models B and C, the fit indices of both models were compared directly, Model C being nested in Model B with six additional degrees of freedom. Model $\mathrm{C}$ necessarily showed a poorer fit, as six paths of this model were fixed. We tested whether Models B and C differed using the $\chi^{2}$ difference test, and in terms of their respective fit to the data by comparing the CFIs of both models. As argued by Cheung and Rensvold (2002), nested models can be considered equivalent when $\triangle \mathrm{CFI}$ is smaller than or equal to .01. In addition, we investigated whether the RMSEA of Model C was within the $90 \%$ confidence interval of the RMSEA of Model B.

In order to test for gender differences in our sample (Hypothesis 4), we compared girls' and boys' mean levels of achievement, self-concept, and enjoyment using $t$-tests. To analyze the relevance of differences, particularly in light of our large sample size, effect sizes (Cohen's $d$; Cohen, 1988) of the differences were also calculated. Finally, we performed a multiple-group analysis, testing for gender invariance of the structural relations in Models A-C (Hypothesis 4). This was done in a stepwise manner (cf., Vandenberg \& Lance, 2000). For each of our three models, we first established measurement invariance across the genders by competitively testing each a model with freely varying measurement weights 
against a model with gender-invariant measurement weights. Subsequently, we tested for invariance of the latent structures in each model by comparing a model having freely varying structural weights with a model having both gender-invariant measurement weights, and gender-invariant structural weights. If this stepwise inclusion of invariance constraints resulted in little or no change in model fit, it could be inferred that the models were structurally equivalent for both subsamples. We again tested the change in model fit using the $\chi^{2}$ difference test, and by comparing selected fit indices (CFI, RMSEA) for the unconstrained and constrained versions of each model.

\section{Results}

\subsection{Domain specificity (Hypothesis 1)}

Mathematics and verbal (languages) achievement scores were moderately correlated (Pearson's $r=.36, p<.001$; see Appendix A), whereas enjoyment of math and verbal classes was virtually unrelated (Pearson's $r=.03, p=.26$ ). Math and verbal self-concepts were weakly negatively related (Pearson's $r=-.14, p<.01$ ). Thus, our results indicate that both academic enjoyment and academic self-concepts are largely organized in domain-specific ways.

\subsection{Achievementlenjoyment relations (Hypothesis 2)}

Results of the SEM analysis for Model A are presented in Fig. 1. Correlations between manifest variables included in our Models A-C are shown in the Appendix A. The pattern of selected fit indices indicated a very good model fit (see Table 1 [A]). Because the $\chi^{2}$ statistic has been shown to be overly sensitive to sample size (e.g., Marsh, Balla, \& McDonald, 1988), the $\chi^{2} / d f$ statistic is not given much consideration in view of the large sample size of 1380 students. As for the within-domain relationships, both path coefficients from achieve-

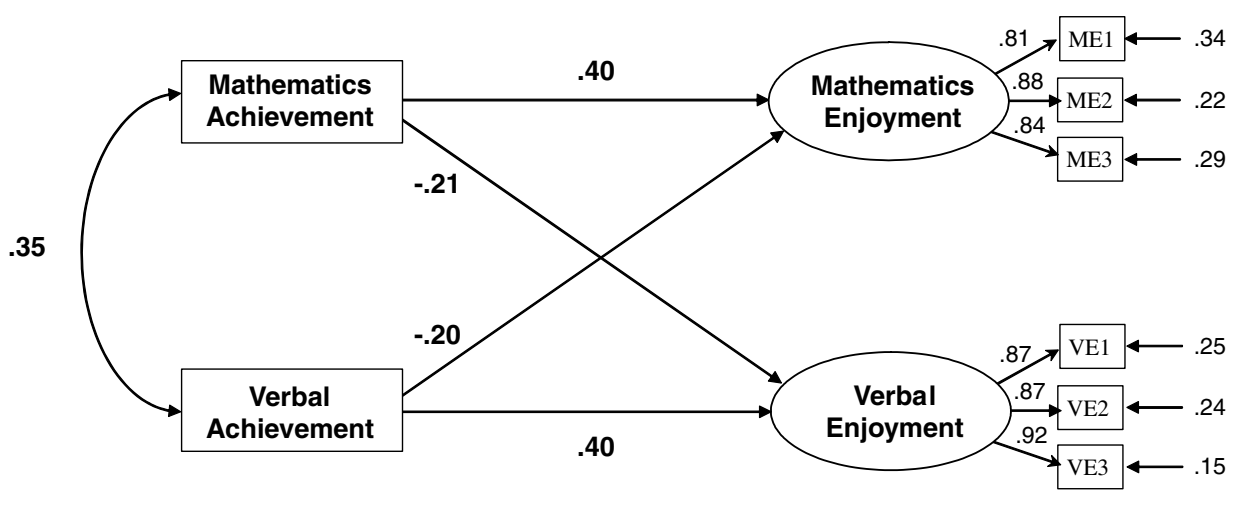

Time 1

Time 2

Fig. 1. Structural parameter estimates of Model A. 
Table 1

CFA Models with achievement, self-concept, and academic enjoyment

\begin{tabular}{lrrrrr}
\hline Models & $\chi^{2}$ & $d f$ & NNFI & CFI & RMSEA \\
\hline (A) Achievement/enjoyment model & 61.81 & 17 & .98 & .99 & .048 \\
(B) Achievement/self-concept/enjoyment; mediational model & 320.03 & 66 & .96 & .97 & .058 \\
(C) Achievement/self-concept/enjoyment; mediational & 359.00 & 72 & .96 & .97 & .059 \\
$\quad$ model; six paths fixed to 0 & & & & &
\end{tabular}

Notes. Models A-C are depicted in Figs. 1-3. NNFI, non-normed fit index (= TLI, Tucker-Lewis index); CFI, comparative fit index; RMSEA, root mean square error of approximation. The $\chi^{2}$ values for null models used to define the NNFI and CFI were $5575.72(d f=28)$ for Model A, and $9132.86(d f=91)$ for Models B and C.

ment to enjoyment were positive and of medium size (they were each $.40 ; p<.01$ ). While controlling for these within-domain effects, the anticipated I/E effect was observed in terms of significant negative cross-domain effects in both directions, with mathematics achievement being negatively related to verbal enjoyment $(-.20, p<.01)$, and verbal performance being negatively related to enjoyment in mathematics $(-.21, p<.01)$. These cross-domain relationships were significant, though weaker, than the within-domain relationships.

\subsection{Mediation processes (Hypothesis 3)}

In Model B (see Fig. 2), we took the mediating role of academic self-concepts into account when analyzing the achievement/enjoyment relations. The fit of this model is

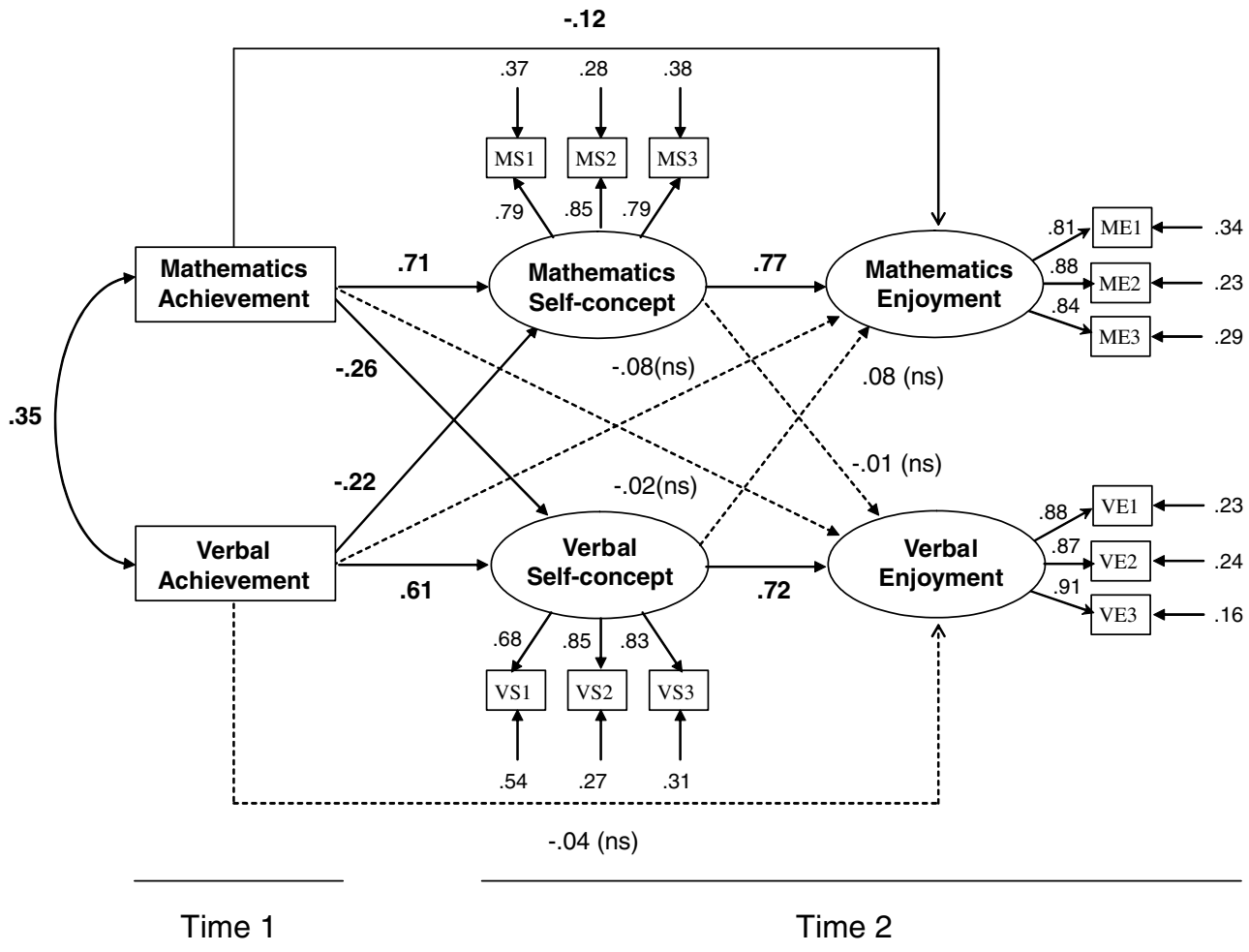

Fig. 2. Structural parameter estimates of Model B (Dotted lines: non-significant paths). 
acceptable (see Table $1[\mathrm{~B}]$ ). Relations between achievement scores and self-concepts reflect the "classical" pattern found in previous research on the I/E-model: concerning the withindomain relationships, achievement scores had strong positive effects on self-concepts (.71/ .61 for Mathematics/German, each $p<.01$ ). Controlling for these within-domain effects, negative cross-domain effects in both directions were found, with achievement in mathematics having a negative effect on verbal self-concept $(-.26, p<.01)$, and verbal performance having a negative effect on math self-concept $(-.22, p<.01)$. In addition, we found strong within-relationships between self-concepts and enjoyment in the two domains (.77/ .72 for mathematics/German, each $p<.01$ ). Cross-domain paths from self-concepts to enjoyment scores were not significant $(-.01$ from mathematics self-concept to verbal enjoyment; .08 from verbal self-concept to enjoyment in mathematics; each $p>.01$ ).

Central for the present research question is the finding that three of the four direct paths (two within- and two cross-domain paths) from achievement to enjoyment were not significant $(p>.01)$. Although the path from mathematics achievement to mathematics enjoyment was significant and even negative in Model B (-.12), its effect size was negligible. The indirect effect of mathematics achievement on mathematics enjoyment through mathematics self-concept was .53-more than four times stronger than this direct effect. For language achievement and language enjoyment, the indirect effect was .44 and the direct path was -.04 (insignificant).

In Model C (see Fig. 3), the four direct (non-mediated) paths from achievement to enjoyment (two within- and two cross-domain paths) were fixed to zero, just like the two cross-domain paths from self-concepts to enjoyment. In this analysis, the critical question

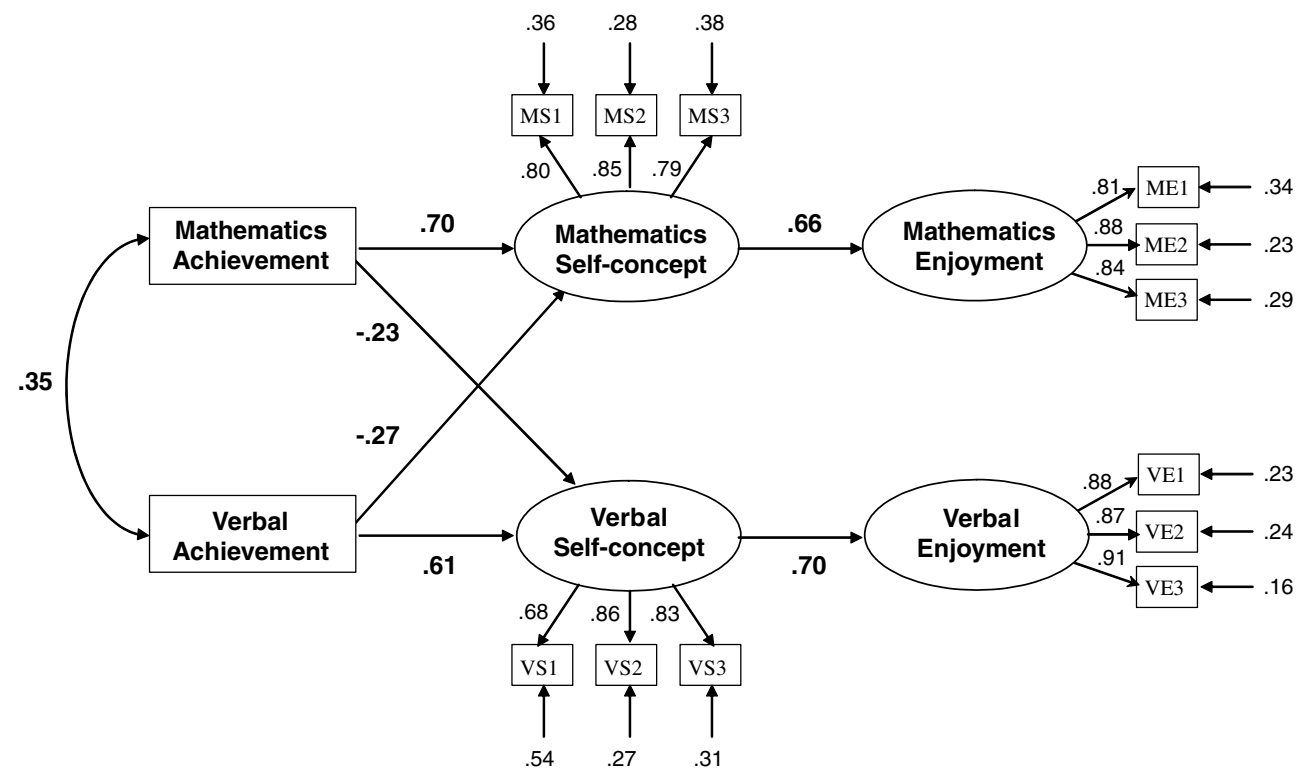

Time 1

Time 2

Fig. 3. Structural parameter estimates of Model C. 
concerned the amount of loss of fit due to these restrictions, as compared to Model B. In terms of the $\chi^{2}$ difference test, the loss of fit indeed was significant $\left(\Delta \chi^{2}=38.97 ; \Delta d f=6\right.$; $p<.01)$. However, research has shown that the $\chi^{2}$ difference test is very conservative with large sample sizes (Brannick, 1995; Kelloway, 1995). In fact, results showed that Models B and $\mathrm{C}$ did not differ in terms of CFI (both .97), and the RMSEA of Model C (.059) to be within the $90 \%$ confidence interval of the RMSEA for Model B ([.052; .065]). Thus, the insignificant loss of fit when setting the six paths of Model B to zero (resulting in Model C) shows that these direct paths can be considered negligible. ${ }^{1}$

\subsection{Gender differences (Hypothesis 4)}

Descriptive scale statistics for girls and boys are presented in Table 2. Mean differences on the study measures were each tested for significance. In line with our hypothesis, we found stereotypic gender differences in means. Boys showed higher scores in math achievement and reported higher levels of mathematics self-concept and enjoyment, whereas girls showed higher scores in verbal achievement and reported higher levels of verbal self-concept and enjoyment. ${ }^{2}$ Although gender differences in math achievement were significant, they were negligible in terms of effect sizes. Although differences in verbal achievement were stronger, these differences were also relatively small in terms of effect sizes (Cohen, 1988).

A first indicator of similarity of structural relations of variables between male and female students were the zero-order correlation coefficients. In Table 2, coefficients for the female subsample are shown above the diagonal, and coefficients for the male subsample below the diagonal. The mean difference of the Fisher's $z$-transformed, zero-order correlations for girls and boys is $.06(\mathrm{SD}=.02$; $\mathrm{Min}=.01, \mathrm{Max}=.10)$, indicating very similar relations for girls and boys (Cohen, 1988).

To assess gender-invariance of relationships on a latent level, a multiple group analysis was performed with Models A to C (Figs. 1-3). In preliminary separate analyses of Models A through $\mathrm{C}$, the models for both genders fit the data well (males/ females: $\mathrm{RMSEA}_{[\text {Model A] }}=.054 / .046, \quad \mathrm{NNFI}_{[\text {Model A] }}=.98 / .99, \mathrm{CFI}_{[\text {Model A] }}=.99 / .99$; $\mathrm{RMSEA}_{[\text {Model B] }}=.052 / .066, \mathrm{NNFI}_{[\text {Model B] }}=.97 / .95, \mathrm{CFI}_{[\text {Model B] }}=.96 / .96 ; \mathrm{RMSEA}_{[\text {Model }}$ $\left.\mathrm{C}]=.053 / .068, \mathrm{NNFI}_{[\text {Model C] }}=.97 / .95, \mathrm{CFI}_{[\text {Model C }]}=.97 / .96\right)$.

\footnotetext{
${ }^{1}$ Model C represents our final model. We tested whether the structural relations among variables in this model changed as a function of age. We calculated the parameters for this model separately for three subsamples, namely, students in grades $5 / 6,7 / 8$, and $9 / 10$. The patterns of structural relationships were very similar across the three subsamples, indicating that the model is valid across age. The fit indices for Model $\mathrm{C}$ were as follows for grade levels $5 / 6,7 / 8$ and 9/10: $\chi^{2}=232 / 199 / 235 ; d f=72 / 72 / 72$; NNFI $=.94 / .95 / .93, \mathrm{CFI}=.96 / .97 / .95$, RMSEA $=.069 /$ $.059 / .075$. The paths for grade levels $5 / 6,7 / 8$, and $9 / 10$ were as follows: mathematics achievement to mathematics self-concept: .66/.72/.69; verbal achievement to verbal self-concept: .59/.52/.65; mathematics achievement to verbal self-concept: $-.21 /-.30 /-.35$; verbal achievement to mathematics self-concept: $-.23 /-.27 /-.25$; mathematics selfconcept to mathematics enjoyment: .59/.71/.62; verbal self-concept to verbal enjoyment: .75/.62/.66. All path coefficients were significant $(p<.01)$.

${ }^{2}$ We also examined whether the mean level differences in our variables changed as a function of grade level. We conducted a multivariate analysis of variance including math and verbal achievement, self-concept, and enjoyment as dependent variables. Gender and grade level (5/6 vs. $7 / 8$ vs. $9 / 10)$ were included in the analysis as fixed factors. The interaction between gender and grade level did not reach statistical significance $(F(12,2476)=1.48$, $p=.12$ ), indicating that gender differences in enjoyment, academic self-concept, and achievement did not change as a function of grade level.
} 
Table 2

Descriptive statistics of scales and zero-order correlation coefficients among measures (positive $t$-values reflect higher scores for boys)

\begin{tabular}{|c|c|c|c|c|c|c|c|c|c|c|c|c|}
\hline \multirow[t]{2}{*}{ Scales } & \multicolumn{2}{|c|}{ Boys $(n=683)$} & \multicolumn{2}{|c|}{ Girls $(n=697)$} & \multirow[t]{2}{*}{$t$-value } & \multirow[t]{2}{*}{ Effect size $d$} & \multicolumn{6}{|c|}{ Zero-order correlation coefficients among measures } \\
\hline & $M$ & SD & $M$ & SD & & & (1) & (2) & (3) & (4) & $(5)$ & (6) \\
\hline (1) Mathematics enjoyment & 9.21 & 3.40 & 8.13 & 3.14 & $6.04^{* *}$ & 0.23 & - & .04 & .59 & -.11 & .30 & -.09 \\
\hline (2) Verbal enjoyment & 7.98 & 3.52 & 9.50 & 3.46 & $-7.99^{* *}$ & -0.31 & .10 & - & -.14 & .59 & -.11 & .24 \\
\hline (3) Mathematics self-concept & 9.47 & 3.27 & 7.94 & 3.21 & $8.58^{* *}$ & 0.33 & .56 & -.08 & - & -.13 & .57 & .06 \\
\hline (4) Verbal self-concept & 9.36 & 3.03 & 10.77 & 2.87 & $-8.79^{* *}$ & -0.34 & -.01 & .54 & -.06 & - & -.04 & .46 \\
\hline (5) Mathematics achievement & 3.97 & 1.03 & 3.84 & 1.01 & $2.24^{*}$ & 0.09 & .29 & -.02 & 61 & -.01 & - & .40 \\
\hline (6) Verbal achievement & 3.78 & 0.85 & 4.16 & 0.83 & $-8.28^{* *}$ & -0.32 & .00 & .28 & .10 & .42 & .37 & - \\
\hline
\end{tabular}

Notes. $t$-values: ${ }^{*} p<.05 ;{ }^{* *} p<.01$. Correlation coefficients: Female sample is shown above the diagonal; male sample is shown below the diagonal. Female sample: $p<.05$ for $|r| \geqslant .07 ; p<.01$ for $|r| \geqslant .10 ; p<.001$ for $|r| \geqslant .12$. Male sample: $p<.05$ for $|r| \geqslant .08 ; p<.01$ for $|r| \geqslant .10 ; p<.001$ for $|r| \geqslant .13$. 
Table 3

Fit Indices for Models with varying equality constraints (males vs. females)

\begin{tabular}{|c|c|c|c|c|c|}
\hline Models & $\chi^{2}$ & $d f$ & NNFI & CFI & RMSEA \\
\hline \multicolumn{6}{|l|}{ Model A } \\
\hline Unconstrained & 85.39 & 34 & .98 & .99 & .037 \\
\hline Equal measurement weights & 90.21 & 38 & .98 & .99 & .035 \\
\hline Equal measurement and structural weights & 93.31 & 42 & .98 & .99 & .033 \\
\hline \multicolumn{6}{|l|}{ Model B } \\
\hline Unconstrained & 409.98 & 132 & .96 & .97 & .043 \\
\hline Equal measurement weights & 422.48 & 140 & .96 & .97 & .042 \\
\hline Equal measurement and structural weights & 431.49 & 152 & .96 & .97 & .040 \\
\hline \multicolumn{6}{|l|}{ Model C } \\
\hline Unconstrained & 448.57 & 144 & .96 & .97 & .043 \\
\hline Equal measurement weights & 460.74 & 152 & .96 & .97 & .043 \\
\hline Equal measurement and structural weights & 464.57 & 158 & .96 & .97 & .042 \\
\hline
\end{tabular}

Notes. Models A-C are depicted in Figs. 1-3. NNFI, non-normed fit index (= TLI, Tucker-Lewis Index); CFI, comparative fit index; RMSEA, root mean square error of approximation.

Next, the equivalence of Models A-C across genders was tested with varying degrees of constraints. Imposing the equality constraint of the measurement weights in the first step did not significantly reduce the fit of Models A through $\mathrm{C}$ (see Table 3; Model A: $\Delta \chi^{2}=4.82, \Delta d f=4, p=.31$; Model B: $\Delta \chi^{2}=12.49, \Delta d f=8, p=.13$; Model C: $\Delta \chi^{2}=12.17$, $\Delta d f=8, p=.14)$. Because the $\chi^{2}$ difference test can be considered a very conservative test in view of our large sample size (Brannick, 1995; Kelloway, 1995), as noted above, this provides strong support for gender invariance of the measurement weights for the constructs under investigation. When the structural weights were also constrained to gender invariance, the $\chi^{2}$ difference test again indicated no significant loss of the fit of Models A through C (see Table 3; Model A: $\Delta \chi^{2}=7.92, \Delta d f=8, p=.44$; Model B: $\Delta \chi^{2}=21.51, \Delta d f=20$, $p=.37$; Model C: $\Delta \chi^{2}=16.00, \Delta d f=14, p=.31$ ).

When assessing loss of model fit due to the imposed equivalence of measurement and structural weights, the CFI was found to remain constant. In terms of the RMSEA, the more constrained models were in fact found to fit the data better (see Table 3). Overall, the results of these nested model comparisons strongly support the premise that the pattern of structural relations between achievement, self-concepts, and enjoyment for male vs. female students did not differ significantly. That is, these results suggest that gender did not moderate the relations between our study measures, thus corroborating the assumed cross-gender universality of these relations.

\section{Discussion}

Students' positive emotions related to learning and achievement have been neglected in educational research until recently. The present study focused on one specific positive emotion, namely, academic enjoyment. More specifically, we examined the relations between this emotion and students' antecedent academic achievement. Our assumptions concerning the achievement/enjoyment relations were based on the I/E model (Marsh, 1986, 1990) and Pekrun's $(2000,2006)$ control-value theory of achievement emotions. More specifically, we analyzed the interrelations of students' achievement, self-concepts, and experiences of 
academic enjoyment as assessed in the two subject areas of mathematics and German language.

In line with our assumptions, and consistent with preliminary findings from previous studies (Goetz, Pekrun, et al., 2006; Pekrun et al., 2002c), our results suggest that academic emotions are, to a great extent, organized along domain-specific lines, similar to academic self-concepts (Möller \& Köller, 2004). Specifically, we found that experiences of enjoyment in mathematics and language classes, as well as math and verbal self-concepts, were largely uncorrelated. As expected, we also found the I/E model to be a valid conceptual framework for understanding how students' achievement relates to their experiences of enjoyment in different academic domains. When taking both within- and cross-domain relations of achievement and enjoyment into account, we found positive within-domain effects of achievement on enjoyment, and negative effects of achievement on experiences of enjoyment in the other subject area, that is, negative cross-domain effects.

Furthermore, in line with mediational assumptions as derived from the I/E model and Pekrun's control-value theory, the findings of structural equation modelling showed that within- and cross-domain achievement/enjoyment relations were largely mediated by students' domain-related academic self-concepts. Consistent with previous findings on the I/E model, achievement had positive within-domain, and negative cross-domain effects on academic self-concept. In addition, in line with the assumptions of the control-value theory, self-concept and enjoyment were positively related within domains, but unrelated across domains. This pattern of findings implies that the effects of achievement on enjoyment are mediated by self-concept. This conclusion is further strengthened by the fact that any direct effects of achievement on enjoyment were non-significant, or negligible in terms of effect size.

Concerning relations between achievement and self-concept, the positive within-domain effects of achievement on self-concepts can be interpreted as resulting from external comparisons influencing the formation of self-concepts (external frame of reference; Marsh, 1986, 1990). The negative cross-domain effects can be interpreted as resulting from dimensional intra-individual comparisons (internal frame of reference).

The combined results of our structural analyses thus imply that the I/E-model is a valid conceptual framework for understanding the effects of students' academic achievement on their enjoyment, and that assumptions of the control-value theory can be used to explain the mediational role of students' self-concepts. These findings contribute to our knowledge of the antecedents of students' academic emotions, and the mechanisms that likely cause these emotions to be organized in domain-specific ways. Specifically, our findings suggest that the domain-specificity of academic enjoyment is due to the weak or nonexistent crossdomain relations of one of its major antecedents, namely students' domain-related academic self-concepts. As emotional experiences other than enjoyment also seem to be organized along domain-specific lines (for anxiety and boredom, see Goetz, Pekrun, et al., 2006), future research on the achievement/self-concept/emotion relations with respect to other academic emotions, such as pride, hope, anxiety, anger or boredom, is warranted.

The present findings based on structural equation modeling of the achievement/selfconcept/enjoyment relations also indicate that the constructs of academic enjoyment and self-concept, even though highly correlated, are empirically distinguishable. Were these two constructs the same, including self-concept as a mediator of the effects of achievement on enjoyment would have attenuated the effects of achievement, but would not have eliminated them completely as was observed in this study (for a similar argumentation concern- 
ing self-concept and anxiety, see Marsh, 1988a, and Schwarzer, 1986). As only non-affective self-concept items were used in this study, the enjoyment and self-concepts scales were clearly distinguishable in terms of both content validity and empirical relations. The relations between achievement, self-concept, and enjoyment would likely have been different if the self-concept measure used had included affective items, in addition to cognitive items. In such a case, the achievement/enjoyment relations likely would not have been eliminated when using self-concept as a mediator.

As to gender differences, we found stereotypic gender differences in mean levels of achievement scores, self-concepts of ability, and academic enjoyment, in line with our assumptions. However, as expected, some of the differences were small in terms of effect sizes, as is consistent with previous findings (e.g., Hyde, 2005). Compared to boys, girls had lower grades, as well as lower self-concepts and less enjoyment in mathematics, and higher grades, self-concepts, and enjoyment in German language classes.

Despite these stereotypic gender differences in mean levels, the pattern of structural relations between achievement, self-concept, and enjoyment was similar for girls and boys. The achievement/self-concept relations found in this study are consistent with findings of previous research on the cross-gender universality of relations between these constructs (Hansford \& Hattie, 1982; Marsh et al., 2005; Valentine et al., 2004). Similarly, the equivalence of achievement/enjoyment relations across the two genders corroborates findings of the study reported by Frenzel et al. (in press). Taken together, our results on the cross-gender universality of relations between achievement, self-concept, and enjoyment demonstrates that gender differences in academic enjoyment cannot be explained by differences in structural relationships. Rather, it can be assumed that these discrepancies are due to gender differences in mean levels of the antecedent variables, including achievement outcomes and selfconcepts (for a similar argumentation regarding relations between competence, beliefs, and emotions, see Frenzel et al., in press).

Concerning gender differences in mean levels of achievement, self-concept, and enjoyment, the overall pattern of results was quite consistent for the verbal domain. Our results with respect to language classes showed gender differences in achievement, as well as academic self-concept and enjoyment in favor of the girls. However, concerning mathematics classes, the question arises as to why clear differences in self-concept and enjoyment in favor of the boys were observed, in spite of the fact that gender differences in achievement outcomes were weak. As structural relations between achievement and self-concepts have been shown to be equal in girls and boys, small gender differences in achievement should lead to small differences in academic self concept and enjoyment.

Nonetheless, this discrepancy involving math-related achievement and self-concept is consistent with previous studies showing higher self-perceptions of math ability in boys, despite similar achievement outcomes across genders (e.g., Frome \& Eccles, 1998; Holling \& Preckel, 2005; Preckel, Goetz, Pekrun, \& Kleine, in press; see also Spelke, 2005). Thus, this suggests that there are factors other than achievement that bolster boys' academic selfconcepts in mathematics, or reduce girls' self-concepts in this domain. Gender-linked stereotypes of domain-related abilities are one candidate for explaining these discrepancies.

Traditionally, girls and mathematics have been considered a "bad fit" by students, teachers, and parents alike. It might be that these kinds of beliefs and stereotypes influence girls and boys academic self-perceptions related to mathematics (cf., Davies \& Spencer, 2005; Forgasz, Leder, \& Kloosterman, 2004). Stereotypes might be at work when self-concepts of ability are developed, in addition to their impact of achievement. Indeed, females 
often think they have to work harder than boys to achieve good results in mathematics (Lupart, Cannon, \& Telfer, 2004).

A limitation of the present study is that experiences of enjoyment were assessed through the use of self-report measures. As self-report measures rely on self-appraisals of emotions, they are also subject to subjective biases of these self-appraisals. The present study shares this feature with numerous other studies on emotions and related constructs based on selfreport assessments. However, self-report measures of emotion are, at present, deemed to be the most reliable, valid, and economic assessment tools available (see Zeidner, 1998 for a discussion of different methods for assessing test anxiety).

\section{Implications}

To enhance the effectiveness of instruction (e.g., by adapting teaching to individual differences; cf., Snow \& Swanson, 1992), educators should be made aware of the domain specificity of students' emotional experiences. Previous studies have shown that teachers tend to perceive individual student characteristics as habitual, domain-transcending attributes (cf., Marsh, 1993; Pohlmann, Möller, \& Streblow, 2004). In view of our findings on the domain-specific organization of academic enjoyment, it can be assumed that teachers' domain-general conceptions can lead to false inferences regarding the emotions experienced by individual students in different domains. For example, a teacher may incorrectly assume that a student who is bored in his or her class also feels bored in most other classes. Such a dispositional, domain-general explanation could result in less responsibility being felt by teachers for students' affective engagement in their own classes.

The results of this study also have implications for how to foster students' positive emotions. Concerning the different ways in which teachers can enhance students' positive affect, such as displaying one's own enthusiasm, making instruction stimulating, assigning authentic tasks, and shaping goal structures in affectively beneficial ways (see Pekrun, 2006; Pekrun et al., in press), the present study has the following implications. Our study revealed that academic enjoyment is strongly related to domain-specific academic self-concepts which, in turn, are related to antecedent academic achievement. By implication, it can be assumed that teachers could attempt to enhance students' academic enjoyment by focusing on improving students' academic skills, a process described by Marsh "as the best way to improve self-concept and interest" (Marsh et al., 2005, p. 413). However, two problems emerge when trying to foster students' self-concepts and enjoyment in this way.

First, it may be that improving students' self-concept and emotions by developing their skills works well only within specific domains. As described in the I/E model, and empirically shown by numerous investigations including the present study, high achievement in one domain (as fostered by skill improvement) can have detrimental effects on students' self-concept in other domains. As a corollary, this skill improvement may also have deleterious consequences for students' enjoyment in other domains. How can this dilemma be resolved? To deal adequately with this problem requires more knowledge about why achievement in one domain has negative effects on students' self-concept in other domains. That is, further knowledge concerning the cognitive processes underlying dimensional comparisons is needed.

A second problem is that improving the skills of an entire class may not enhance individual student's experiences of enjoyment, because students evaluate their skills and achievement relative to their classmates, and their relative academic standing in the class 
may remain unchanged. Thus, improving academic skills may not be the most effective means of enhancing students' self-concepts and positive emotions. One solution to this problem may be to encourage teachers to deemphasize social comparison in the classroom, and instead adopt an individual frame of reference when providing achievement-related feedback (i.e., ipsative teacher feedback).

In fact, the most effective way of improving positive emotions in the classroom may be to enhance students' self-concepts in a given domain and thereby strengthen their enjoyment in that domain. Further, based on the results of this study showing strong withindomain, but no cross-domain relations between academic self-concepts and enjoyment, negative effects on enjoyment in other academic domains would not be anticipated. Our findings thus suggest that teachers could make an effort to foster students' positive emotions by helping them to develop positive self-concepts of ability (e.g., by providing positive competence feedback specific to that students' academic progress).

Finally, the findings of our study imply that there are stereotypic gender differences in mean levels of academic achievement, self-concepts, and enjoyment in mathematics and language classes. Although gender differences in these variables are relatively weak in terms of effect sizes (see also Hyde et al., 1990), they can be of considerable practical importance for college course enrollment and career choices. As argued above, gender stereotyping (e.g., the perception of mathematics as a male-oriented academic domain) is assumed to be one critical factor underlying these gender differences. At the same time, however, the results of this study suggest that the interrelations between achievement, self-concept, and enjoyment are invariant across the two genders. This finding is encouraging for educators in implying that any intervention attempting to foster students' emotions by enhancing their achievement and self-concepts should be equally effective for male and female students.

\section{Appendix A}

Means, standard deviations, and correlations for manifest variables of the structural model

Variables $\quad M \quad$ SD Correlation coefficient (Pearson)

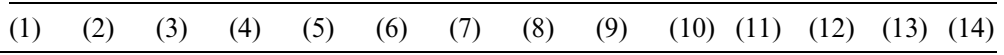

(1) ME1

(2) ME2

(3) ME3

(4) VE1

(5) VE2

(6) VE3

(7) MS1

(8) MS2

(9) MS3

(10) VS1

(11) VS2

(12) VS3

(13) Math Ach

$2.86 \quad 1.15-$

$\begin{array}{llll}3.01 & 1.29 & .71-\end{array}$

$2.81 \quad 1.24$

$2.88 \quad 1.30$

$\begin{array}{ll}3.04 & 1.29\end{array}$

$\begin{array}{ll}2.83 & 1.26\end{array}$

$\begin{array}{lll}3.14 & 1.08\end{array}$

$.68 \quad .76-$

.03

.02

$.03 \quad .03-$

$.02 \quad .03$

.01

.02

$.04 \quad .81-$

$.04 \quad .74 \quad .78-$

$\begin{array}{ll}2.63 & 1.42\end{array}$

.52

$\begin{array}{llll}.40 & -.10 & -.11 & -.11-\end{array}$

2.931 .27

.54

$\begin{array}{llll}.53 & -.15 & -.14 & -.15 \\ .42 & -.11 & -.11 & -.11\end{array}$

$\begin{array}{lllll}3.16 & 1.11 & -.08 & -.06 & -.04\end{array}$

$.43 \quad .46$

$\begin{array}{llllll}3.72 & 1.23 & -.10 & -.07 & -.09\end{array}$

.36

.46

$\begin{array}{rrr}.11 & .64 \quad .65-\end{array}$

$\begin{array}{llllll}3.19 & 1.20 & -.10 & -.07 & -.07\end{array}$

$\begin{array}{rr}.53 & .55 \\ -\end{array}$

$\begin{array}{lllll}.48 & -.01 & -.12 & -.06 & -\end{array}$

$3.90 \quad 1.02$

26

$\begin{array}{lllll}.38 & -.03 & -.14 & -.14 & .56\end{array}$

$\begin{array}{rrrrrr}.55 & .61 & -.09 & -.18 & -.11 & .70\end{array}$

$\begin{array}{lllllllllllllllll}\text { (14) Verbal Ach } & 3.97 & .86 & -.09 & -.06 & -.07 & .26 & .25 & .30 & .09 & -.03 & .02 & .47 & .35 & .38 & .36 & -\end{array}$

Notes. ME1-ME3, mathematics enjoyment; VE1-VE3, verbal enjoyment (German); MS1-MS3, mathematics self-concept; VS1-VS3, verbal self-concept (German); Math Ach, mathematics achievement; Verbal Ach, verbal achievement (German). Scores for enjoyment and self-concepts ranged from 1 (strongly disagree) to 5 (strongly agree) and achievement scores ranged from 1 to 6 with high numbers indicating good achievement results. $p<.05$ for $|r| \geqslant .05 ; p<.01$ for $|r| \geqslant .07 ; p<.001$ for $|r| \geqslant .09 . N=1380$. 


\section{References}

Abu-Hilal, M. M., \& Bahri, T. M. (2000). Self-concept: the generalizability of research on the SDQ, Marsh/Shavelson model and I/E frame of reference model to the United Arab Emirates students. Social Behavior and Personality, 28, 309-322.

Aspinwall, L. G. (1998). Rethinking the role of positive affect in self-regulation. Motivation and Emotion, 22(1), 132.

Bentler, P. M. (1990). Comparative fit indexes in structural models. Psychological Bulletin, 107, $238-246$.

Bong, M. (1998). Tests of the internal/external frames of reference model with subject-specific academic selfefficacy and frame-specific academic self-concepts. Journal of Educational Psychology, 90, 102-110.

Bong, M. (2001). Between- and within-domain relations of academic motivation among middle and high school students: self-efficacy, task-value and achievement goals. Journal of Educational Psychology, 93(1), 23-34.

Bong, M., \& Clark, R. E. (1999). Comparison between self-concept and self-efficacy in academic motivation research. Educational Psychologist, 34, 139-153.

Bong, M., \& Skaalvik, E. M. (2003). Academic self-concept and self-efficacy: how different are they really? Educational Psychology Review, 15(1), 1-40.

Brannick, M. T. (1995). Critical comments on applying covariance structure modeling. Journal of Organizational Behavior, 16, 201-213.

Carol, S. (1986). A question of competence: the effects of competence and task feedback on intrinsic interest. Journal of Personality and Social Psychology., 51(5), 918-931.

Carol, S. (1989). Competence feedback, task feedback, and intrinsic interest: An examination of process and context. Journal of Experimental Social Psychology, 25(4), 343-361.

Cheung, G. W., \& Rensvold, R. B. (2002). Evaluating Goodness-of-Fit Indexes for testing measurement invariance. Structural Equation Modeling, 9, 233-255.

Cohen, J. (1988). Statistical power analysis for the behavioural sciences (2nd ed.). Hillsdale, NJ: Erlbaum.

Crain, R. M. (1996). The influence of age, race, and gender on child and adolescent multidimensional self-concept. In B. A. Bracken (Ed.), Handbook of self-concept: Developmental, social, and clinical considerations (pp. 395420). Oxford, England: Wiley.

Davies, P. G., \& Spencer, S. J. (2005). Women's understanding in quantitative domains through the lens of stereotype threat. In A. M. Gallagher \& J. C. Kaufman (Eds.), Gender differences in mathematics (pp. 172-188). Cambridge: University Press.

Deaux, K. (1977). Sex differences. In T. Blass (Ed.), Personality variables in social behavior (pp. 357-372). Hillsdale, NJ: Erlbaum.

Efklides, A., \& Volet, S. (Eds.). (2005). Feelings and emotions in the learning process [Special issue]. Learning and Instruction, 15(5).

Everson, H. T., Tobias, S., Hartman, H., \& Gourgey, A. (1993). Test anxiety and the curriculum: the subject matters. Anxiety, Stress and Coping: An International Journal, 6(1), 1-8.

Ewert, O. (1979). Eine deutsche Version der Sears Self-concept Inventory Scale [Sears Self-Concept Inventory Scale-German version]. In S. H. Filipp (Ed.), Selbstkonzept-Forschung (pp. 191-202). Stuttgart: Klett.

Forgasz, H. J., Leder, G. C., \& Kloosterman, P. (2004). New Perspectives on the gender stereotyping of mathematics. Mathematical Thinking and Learning, 6, 389-420.

Fredrickson, B. L. (2001). The role of positive emotions in positive psychology. American Psychologist, 56(3), 218-226.

Frenzel, A. C., Pekrun, R., \& Goetz, T. (in press). Girls and Mathematics - A “Hopeless” Issue? a control-value approach to gender differences in emotions towards mathematics. European Journal of Psychology of Education.

Frome, P. M., \& Eccles, J. S. (1998). Parents' influence on children's achievement-related perceptions. Journal of Personality and Social Psychology, 74, 435-452.

Goetz, T. (2004). Emotionales Erleben und selbstreguliertes Lernen bei Schülern im Fach Mathematik [Students' emotions and self-regulated learning in mathematics]. Muenchen: Utz.

Goetz, T., \& Frenzel, A. C. (2006). Relations between achievement emotions and self-concept of ability in mathematics (Technical report). University of Munich: Department of Psychology.

Goetz, T., Frenzel, A. C., Pekrun, R., \& Hall, N. C. (2006). The domain specificity of academic emotional experiences. Journal of Experimental Education, 75(1), 5-29.

Goetz, T., Pekrun, R., Zirngibl, A., Jullien, S., Kleine, M., vom Hofe, R., et al. (2004). Leistung und emotionales Erleben im Fach Mathematik: Längsschnittliche Mehrebenenanalysen [Academic achievement and emotions 
in mathematics: a longitudinal multilevel analysis perspective]. Zeitschrift für Pädagogische Psychologie, 18(4), 201-212.

Goetz, T., Pekrun, R., Hall, N. C., \& Haag, L. (2006). Academic emotions from a social-cognitive perspective: antecedents and domain specificity of students' affect in the context of Latin instruction. British Journal of Educational Psychology, 76, 289-308.

Hanna, G. (2000). Declining gender differences from FIMS to TIMSS. International Reviews on Mathematical Education, 32, 11-17.

Hansford, B. C., \& Hattie, J. A. (1982). The relationship between self and achievement/performance measures. Review of Educational Research, 52, 123-142.

Helmke, A. (1993). Die Entwicklung der Lernfreude vom Kindergarten bis zur 5. Klassenstufe [The development of learning-related enjoyment from Kindergarten to grade 5]. Zeitschrift für Pädagogische Psychologie, 7(2-3), 77-86.

Hembree, R. (1990). The nature, effects, and relief of mathematics anxiety. Journal for Research in Mathematics Education, 21(1), 33-46.

Hidi, S., Renninger, K. A., \& Krapp, A. (2004). Interest, a motivational variable that combines affective and cognitive functioning. In D. Y. Day \& R. J. Sternberg (Eds.), Motivation, emotion, and cognition: Integrative perspectives on intellectual functioning and development (pp. 89-115). Mahwah, NJ: Lawrence Erlbaum Associates Publishers.

Holling, H., \& Preckel, F. (2005). Self-estimation of intelligence-methodological approaches and gender differences. Personality and Individual Differences, 38, 503-517.

Hu, L., \& Bentler, P. M. (1999). Cutoff criteria of fit indexes in covariance structure analysis: conventional criteria versus new alternatives. Structural Equation Modeling, 6, 1-55.

Hyde, J. S. (2005). The gender similarities hypothesis. American Psychologist, 60(6), 581-592.

Hyde, J. S., Fennema, E., Ryan, M., Frost, L. A., \& Hopp, C. (1990). Gender comparisons of mathematics attitudes and affect: a meta-analysis. Psychology of Women Quarterly, 14, 299-324.

Jerusalem, M., \& Mittag, W. (1999). Selbstwirksamkeit, Bezugsnormen, Leistung und Wohlbefinden in der Schule [Self-efficacy, reference-norms, achievement, and well-being at school]. In M. Jerusalem \& R. Pekrun (Hrsg.), Motivation und Leistung (pp. 223-245). Göttingen: Hogrefe.

Jöreskog, K. G., \& Sörbom, D. (2002). LISREL 8.53 (Update December 2002) [Computer Software]. Chicago: Scientific Software International.

Linnenbrink, E. A. (Ed.). (2006). Emotion research in education: Theoretical and methodological perspectives on the integration of affect, motivation, and cognition [Special issue]. Educational Psychology Review, 18(4).

Lupart, J. L., Cannon, E., \& Telfer, J. O. (2004). Gender differences in adolescent academic achievement, interests, values, and life-role expectations. High Ability Studies, 15, 25-42.

Kelloway, E. K. (1995). Structural equation modeling in perspective. Journal of Organizational Behavior, 16, $215-224$.

Ma, X. (1999). A meta-analysis of the relationship between anxiety toward mathematics and achievement in mathematics. Journal for Research in Mathematics Education, 30(5), 520-540.

Marsh, H. W. (1984). Relations among dimensions of self-attribution, dimensions of self-concept, and academic achievements. Journal of Educational Psychology, 76, 1291-1308.

Marsh, H. W. (1986). Verbal and math self-concepts: an internal/external frame of reference model. American Educational Research Journal, 23, 129-149.

Marsh, H. W. (1987). The big-fish-little-pond effect on academic self-concept. Journal of Educational Psychology, $79,280-295$.

Marsh, H. W. (1988a). The content specificity of math and English anxieties: the high school and beyond study. Anxiety Research, 1, 137-149.

Marsh, H. W. (1988b). Self Description Questionnaire: a theoretical and empirical basis for the measurement of multiple dimensions of preadolescent self-concept. A test manual and a research monograph. San Antonio, TX: Psychological Corporation.

Marsh, H. W. (1990). Influences of internal and external frames of reference on the formation of math and English self-concepts. Journal of Educational Psychology, 82, 107-116.

Marsh, H. W. (1993). Academic self-concept: Theory measurement and research. In J. Suls (Ed.), Psychological perspectives on the self (Vol. 4, pp. 59-98). Hillsdale: Erlbaum.

Marsh, H. W., Balla, J. R., \& McDonald, R. P. (1988). Goodness-of-fit indexes in confirmatory factor analysis: the effect of sample size. Psychological Bulletin, 103, 391-410.

Marsh, H. W., \& Yeung, A. S. (1996). The distinctiveness of affects in specific school subjects: an application of confirmatory factor analysis with the National Educational Londitudinal Study of 1988. American Educational Research Journal, 33(3), 665-689. 
Marsh, H. W., \& Yeung, A. S. (1998). Longitudinal structural equation models of academic self-concept and achievement: gender differences in the development of math and English constructs. American Educational Research Journal, 35, 705-738.

Marsh, H. W., Trautwein, U., Lüdtke, O., Köller, O., \& Baumert, J. (2005). Academic self-concept, interest, grades, and standardized test scores: reciprocal effects models of causal ordering. Child Development, 76(2), 397-416.

Meece, J. L., Wigfield, A., \& Eccles, J. S. (1990). Predictors of math anxiety and its influence on young adolescents' course enrollment intentions and performance in mathematics. Journal of Educational Psychology, 82, 60-70.

Meyer, M. R., \& Koehler, M. S. (1990). Internal influences on gender differences in mathematics. In E. Fennema \& G. C. Leder (Eds.), Mathematics and gender (pp. 60-95). New York: Teachers College, Columbia University.

Möller, J., \& Köller, O. (2001). Frame of reference effects following the announcement of exam results. Contemporary Educational Psychology, 26, 277-287.

Möller, J., \& Köller, O. (2004). Die Genese akademischer Selbstkonzepte: Effekte dimensionaler und sozialer Vergleiche [On the development of academic self-concepts: the impact of social and dimensional comparisons]. Psychologische Rundschau, 55(1), 19-27.

Pekrun, R. (1992). The impact of emotions on learning and achievement: towards a theory of cognitive/motivational mediators. Applied Psychology: An International Review, 41(4), 359-376.

Pekrun, R. (2000). A social-cognitive, control-value theory of achievement emotions. In J. Heckhausen (Ed.), Motivational psychology of human development (pp. 143-163). Oxford: Elsevier.

Pekrun, R. (2006). The control-value theory of achievement emotions: Assumptions, corollaries, and implications for educational research and practice. Educational Psychology Review, 18, 315-341.

Pekrun, R., Elliot, A. J., \& Maier, M. A. (2006). Achievement goals and discrete achievement emotions: a theoretical model and prospective test. Journal of Educational Psychology, 98, 583-597.

Pekrun, R., Frenzel, A. C., Goetz, T., \& Perry, R. P. (in press). The control-value theory of achievement emotions: An integrative approach to emotions in education. In P.A. Schutz \& R. Pekrun (Eds.), Emotions in education. San Diego: Academic Press.

Pekrun, R., Goetz, T., Titz, W., \& Perry, R. P. (2002a). Positive emotions in education. In E. Frydenberg (Ed.), Beyond coping: Meeting goals, visions, and challenges (pp. 149-174). Oxford, UK: Elsevier.

Pekrun, R., Goetz, T., Titz, W., \& Perry, R. P. (2002b). Academic emotions in students' self-regulated learning and achievement: a program of qualitative and quantitative research. Educational psychologist, 37(2), 91-105.

Pekrun, R., Goetz, T., Titz, W., \& Perry, R. P. (2002c, April). Control-value theory of academic emotions: Individual and social antecedents of students' domain-specific emotions. Paper presented at the annual meeting of the American Educational Research Association, New Orleans, LA.

Pekrun, R., Goetz, T., \& Frenzel, A. C. (2005). Academic Emotions Questionnaire-Mathematics (AEQ-M)—user's manual. University of Munich: Department of Psychology.

Pekrun, R., Goetz, T., \& Perry, R. P. (2005). Academic Emotions Questionnaire (AEQ)—user's manual. University of Munich: Department of Psychology.

Pekrun, R., Goetz, T., Perry, R., Kramer, K., Hochstadt, M., \& Molfenter, S. (2004). Beyond test anxiety: development and validation of the Test Emotions Questionnaire (TEQ). Anxiety, Stress, and Coping, 17, 287-316.

Pekrun, R., \& Zirngibl, A. (2004). Schülermerkmale im Fach Mathematik [Student characteristics in mathematics]. In M. Prenzel, J. Baumert, W. Blum, R. Lehmann, D. Leutner, \& M. Neubrand (Eds.), PISA 2003. Der Bildungsstand der Jugendlichen in Deutschland - Ergebnisse des zweiten internationalen Vergleichs (pp. 191-210). Muenster: Waxmann.

Pohlmann, B., Möller, J., \& Streblow, L. (2004). Zur Fremdeinschätzung von Schülerselbstkonzepten durch Lehrer und Mitschüler [On students' self-concepts inferred by teachers and classmates]. German Journal of Educational Psychology, 18(3/4), 157-169.

Preckel, F., Goetz, T., Pekrun, R., \& Kleine, M. (in press). Gender differences in gifted and average-ability students: Comparing girls' and boys' achievement, self-concept, interest, and motivation in mathematics. Gifted Child Quarterly.

Roseman, I. J., \& Smith, C. A. (2001). Appraisal theory: overview, assumptions, varieties, controversies. In K. R. Scherer, A. Schorr, \& T. Johnstone (Eds.), Appraisal processes in emotion (pp. 3-19). Oxford, UK: Oxford University Press.

Schutz, P. A., \& Lanehart, S. L. (Eds.). (2002). Emotions in education [Special issue]. Educational Psychologist, $37(2)$.

Schutz, P. A., \& Pekrun, R. (Eds.). (in press). Emotions in education. San Diego: Academic Press.

Schwarzer, R. (1986). Self-related cognitions in anxiety and motivation: an introduction. In R. Schwarzer (Ed.), Self-related cognitions in anxiety and motivation (pp. 1-17). Hillsdale, NJ: Erlbaum. 
Seegers, G., \& Boekaerts, M. (1996). Gender-related differences in self-referenced cognitions in relation to mathematics. Journal for Research in Mathematical Education, 27, 215-240.

Seligman, M. E. P., \& Csikszentmihalyi, M. (2000). Positive psychology: An introduction. American Psychologist, 55(1), 5-14.

Skaalvik, E. M., \& Rankin, R. J. (1995). A test of the internal/external frame of reference model at different levels of math and verbal self-perception. American Educational Research Journal, 35, 161-184.

Skinner, E. A. (1996). A guide to constructs of control. Journal of Personality and Social Psychology, 71, 549-570.

Snow, R. E., \& Swanson, J. (1992). Instructional psychology: aptitude, adaptation, and assessment. Annual Review of Psychology, 43, 586-626.

Spelke, E. S. (2005). Sex differences in intrinsic aptitude for mathematics and science? A critical review. American Psychologist, 60(9), 950-958.

Steiger, J. H., \& Lind, J. C. (1980, June). Statistically based tests for the number of common factors. Paper presented at the Psychometric Society Annual Meeting, Iowa City, IA.

Stevenson, H. W., \& Newman, R. S. (1986). Long-term prediction of achievement and attitudes in mathematics and reading. Child Development, 57(3), 646-659.

Stipek, D. J., \& Mason, T. C. (1987). Attributions, emotions, and behavior in the elementary school classroom. Journal of Classroom Interaction, 22(2), 122-130.

Stumpf, H., \& Stanley, J. C. (1998). Stability and change in gender-related differences on the college board advanced placement and achievement tests. Current Directions in Psychological Science, 7(6), $192-196$.

Tucker, L. R., \& Lewis, C. (1973). A reliability coefficient for maximum likelihood factor analysis. Psychometrika, $38(1), 1-10$.

Valentine, J. C., DuBois, D. L., \& Cooper, H. (2004). The relation between self-beliefs and academic achievement: a meta-analytic review. Educational Psychologist, 39, 111-133.

Vandenberg, R. J., \& Lance, C. E. (2000). A review and synthesis of the measurement invariance literature: suggestions, practices, and recommendations for organizational research. Organizational Research Methods, 3, 4-69.

Weiner, B. (1985). An attributional theory of achievement motivation and emotion. Psychological Review, 92(4), 548-573.

Weiner, B. (2001). Intrapersonal and interpersonal theories of motivation from an attribution perspective. In S. Farideh \& C. Chi-yue (Eds.), Student motivation: The culture and context of learning. Plenum series on human exceptionality (pp. 17-30). Dordrecht, Netherlands: Kluwer Academic Publishers.

Wigfield, A., Battle, A., Keller, L. B., \& Eccles, J. S. (2002). Sex differences in motivation, self-concept, career aspiration, and career choice: implications for cognitive development. In R. De Lisi \& A. McGillicuddy-De Lisi (Eds.), The development of sex differences in cognition (pp. 93-124). Westport, CT, US: Ablex Publishing.

Wylie, R. C. (1979). The self-concept(Vol. 2). Lincoln: University of Nebraska Press.

Zeidner, M. (1998). Test anxiety: The state of the art. New York: Plenum Press.

Zeidner, M., \& Safir, M. P. (1989). Sex, ethnic, and social differences in test anxiety among Israeli adolescents. Journal of Genetic Psychology, 150, 175-185. 